\title{
Discrete roles of canonical and non-canonical Wnt signaling in hematopoiesis and lymphopoiesis
}

\author{
F Famili ${ }^{1}$, BAE Naber ${ }^{1,2}$, S Vloemans ${ }^{1}$, EFE de Haas ${ }^{1}$, MM Tiemessen ${ }^{1,3}$ and FJT Staal ${ }^{*, 1}$
}

The mechanisms that regulate proliferation, fate decisions and differentiation of hematopoietic stem cells (HSC) and thymic stem cells are highly complex. Several signaling pathways including Wnt signaling have important roles during these processes. Both canonical and non-canonical Wnt signaling are important in normal and malignant hematopoiesis and lymphoid development, yet their precise roles are controversial. In a side-by-side comparison, we investigated the roles of the canonical and non-canonical Wnt pathway in hematopoiesis and thymopoiesis. As complete loss-of-function models for non-canonical Wnt signaling are not yet available and highly complex for canonical Wnt signaling, we decided to use a gain-of-function approach. To this end, Wnt3a and Wn5a, two well-known prototypical canonical and non-canonical Wnt ligands were produced in hematopoiesis supporting stromal assays. High levels of Wnt3a signaling blocked T-cell development at early stages, whereas intermediate levels accelerated T-cell development. In contrast, Wnt5a signaling prompted apoptosis in developing thymocytes, without affecting differentiation at a particular stage. To explore the role of Wnt3a and Wnt5a in vivo, we transduced HSCs isolated from fetal liver, transduced with Wnt3a and Wnt5a vectors, and performed reconstitution assays in irradiated C57BI/6 mice. Wnt3a overexpression led to increased lymphopoiesis, whereas Wnt5a augments myelopoiesis in the bone marrow (BM) and spleen. Thus, the canonical and noncanonical Wnt signaling have discrete roles in hematopoiesis and thymopoiesis, and understanding their right dose of action is crucial for prospective translational applications.

Cell Death and Disease (2015) 6, e1981; doi:10.1038/cddis.2015.326; published online 19 November 2015

The development of blood and immune cells are highly complex and regulated processes. A wide variety of signaling pathways has been implicated in these processes. Several developmental signals have key roles in both the bone marrow (BM) and thymus, such as BMP, Wnt and Notch signaling. ${ }^{1,2}$ Hematopoietic stem cells (HSC) are rare BM-residing cells with the capacity to self-renew and differentiate into all blood cell lineages. All blood cells, except T lymphocytes, develop within the BM. Different types of progenitor cells migrate from $\mathrm{BM}$ to thymus where they develop to mature T cells. ${ }^{3,4}$ The nature of these cells is still subject of debate. As only few early thymic progenitors (ETPs) arrive in the thymus ( $<10 /$ day), massive proliferation is necessary to establish a pool of T-cell progenitors. ${ }^{5}$ During development, these immature thymocytes gradually lose their proliferative and multilineage potential, and initiate a T-cell developmental program, a process termed T-cell commitment. Notch signaling has been shown to have an important role during T-cell commitment by directly or indirectly upregulation of T-cell-specific genes including Ptcra, Cd3e and Zap 70.6,7 Other soluble factors including Wnt ligands might also be crucial for T-cell proliferation and commitment. ${ }^{8-10}$

Early stages of T-cell development are phenotypically characterized by absence of the mature T-cell markers CD4 and CD8 and referred to as double negative (DN). ${ }^{11} \mathrm{DN}$ stages are subdivided into four stages. DN1: CD44+ CD25-, DN2: CD44+ CD25+, DN3: CD44-CD25+ and DN4: CD44- CD25-. ${ }^{8,12}$ It is believed that T-cell commitment occurs at the transition of DN2 to DN3 stages. ${ }^{13,14}$ Afterwards, thymocytes develop to the immature single positive (ISP) stage defined as CD3CD8+. Thymocytes with functionally rearranged T-cell receptors (TCRs) develop to next stage, which is double positive (DP) for CD4 and CD8 and finally they become mature single positives (SP) ${ }^{12}$ either CD4 or CD8. ${ }^{7-9}$

Thymic epithelial cells (TECs) provide a unique environment for ETPs to develop towards T cells. ${ }^{15,16}$ TECs also express high levels of Notch ligands including Delta like ligands 1 and 4, soluble Wnt ligands and IL-7, which all are crucial for early stages of T-cell development. ${ }^{17}$

The Wnt signaling pathway is subdivided into canonical $(\beta$-catenin dependent) and non-canonical ( $\beta$-catenin independent) pathways. Binding of different Wnt proteins to frizzled (Fzd) receptors can trigger different Wnt pathways. The diversity of ligands and receptors makes the study of Wnt signaling from point of view of cell surface receptors and ligands challenging. Wnt proteins function as proliferationinducing growth factors but may also affect cell-fate decisions, apoptosis and quiescence. ${ }^{18}$ Canonical Wnt proteins bind to

\footnotetext{
1Department of Immunohematology and Blood Transfusion (IHB), Leiden University Medical Center, Leiden, The Netherlands

*Corresponding author: FJT Staal, Department of Immunohematology and Blood Transfusion (IHB), Leiden University Medical Center, Albinusdreef 2, building 1, L3-35, PO Box 9600, Leiden 2300 RC, The Netherlands. Tel: +31 71526 4657; Fax: +31 71526 5267; E-mail: F.J.T.Staal@ lumc.nl

${ }^{2}$ Current address: Department of Immunology, Erasmus MC, Rotterdam, The Netherlands

${ }^{3}$ Current address: Janssen Prevention Center, Leiden, The Netherlands

Abbreviations: BM, bone marrow; DLL, delta like; DN, double negative; DP, double positive; ETP, early thymic progenitor; Fzd, frizzled; GFP, green fluorescent protein; HSC, hematopoietic stem cell; ISP, immature single positive; LEF, lymphocyte enhancer factor; LSK, Lin-Sca1+c-Kit+; MPP, multipotent progenitor; SP, single positive; TCF, T-cell factor; TEC, thymic epithelial cell

Received 14.7.15; revised 30.9.15; accepted 09.10.15; Edited by H-U Simon
} 
their receptors, thereby preventing proteosomal degradation of the Wnt-mediator $\beta$-catenin. Subsequently, $\beta$-catenin trans locates to the nucleus where it will form an active transcription complex with one of the four transcription factors downstream of the Wnt pathway: Tcf1, 3 or 4 (T-cell Factor 1, 3, 4) or Lef1 (lymphocyte-enhancer-binding factor). Upon transcriptional activation, several target genes will be activated including Axin2, c-fos, c-myc and many others, which are important for proliferation and/or cell-fate decisions. Non-canonical Wnt signaling involves recognition of distinct Wnt ligands by a cognate Frz-LRP receptor complex, heterotrimeric G protein activation of phospholipase $\mathrm{C}$ as well as the release of intracellular $\mathrm{Ca}^{2+}$ ions. Non-canonical Wnt signaling also regulates cellular polarization and migration (the so-called planar-cell-polarity pathway). ${ }^{9,10,18-21}$

A large body of evidence has shown the significance of canonical Wnt signaling during T-cell development. Generation of Tcf1 KO mice provided the first evidence of a Wht signaling effect during T-cell development. ${ }^{22}$ Tcf1 deficiency partially blocks T-cell development at various early DN stages, resulting in fewer mature T cells and smaller thymus. In addition, Tcf1/Lef double KO mice have a complete block at the ISP stage, which indicates redundancy between these factors during thymocyte development. ${ }^{23}$

Similar to Tcf1 deficiency, fetal thymic organ cultures using Wnt3a-deficient progenitors exhibited progressively

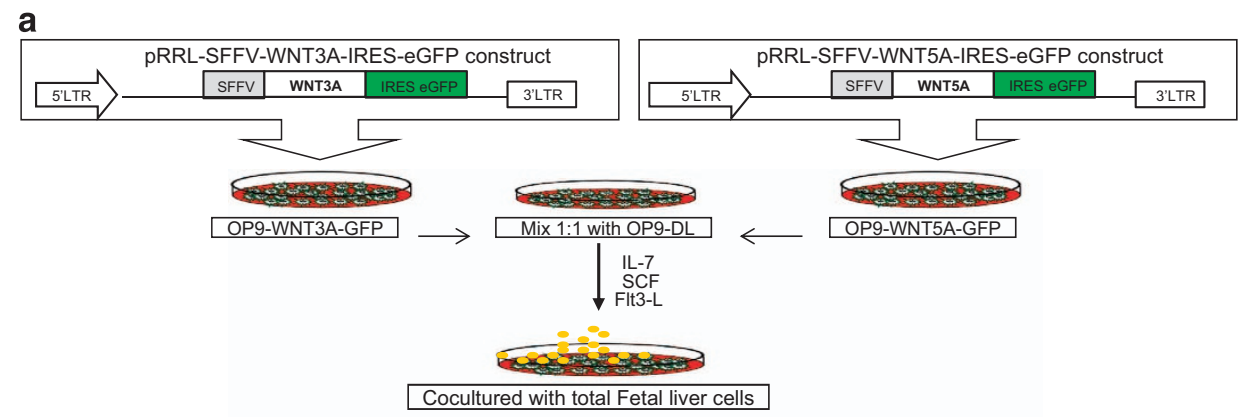

b
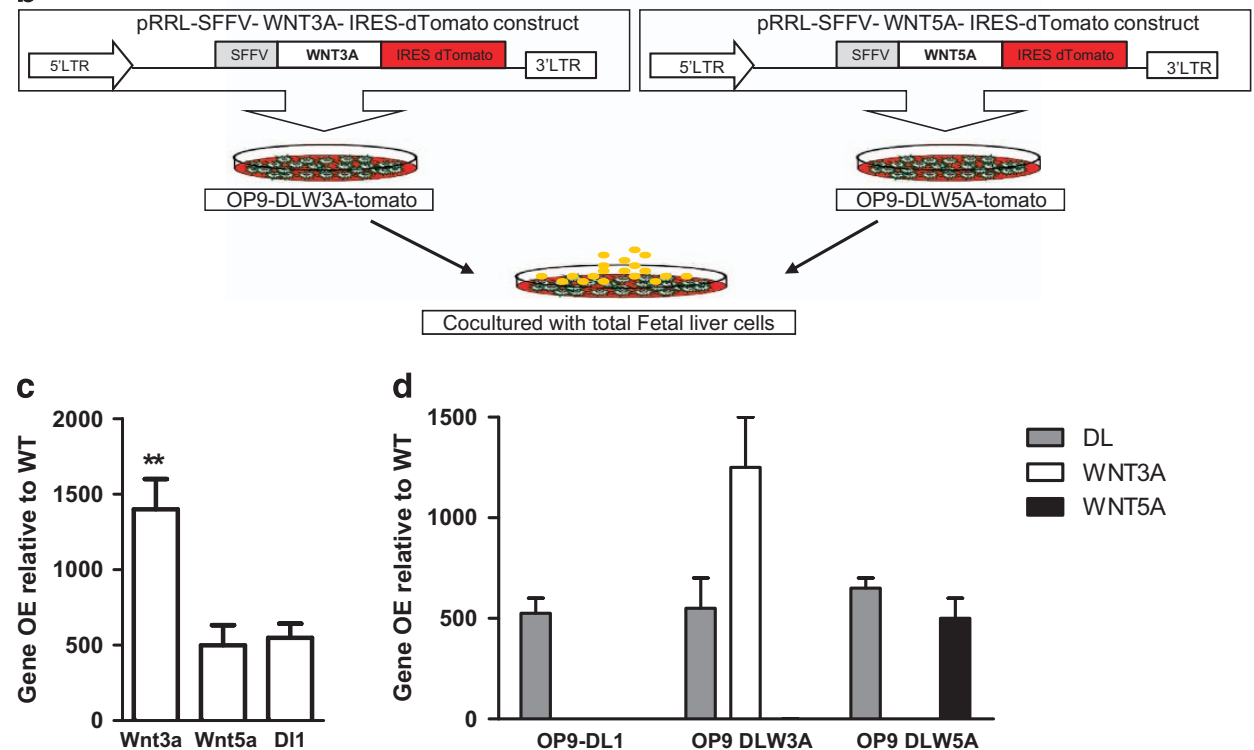

d
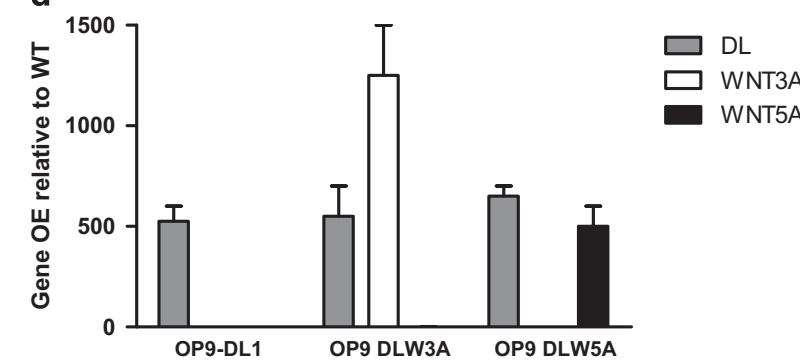

Figure 1 Canonical Wnt3a overexpression blocks T-cell development at early stages. (a) Experimental design. OPg-WT cell lines were transduced with pRRL-SFFV-Wnt3aGFP or pRRL-SFFV-Wnt5a-GFP lentiviral constructs, selected by cell sorting on high GFP expression and for experiments mixed with OP9-DI1-GFP. Stem cells from E14 fetal liver cells were co-cultured with OP9-WT/Dl1 mixed 1:1 as a control, or OP9-Wnt3a/Dl1 1:1, or OP9-Wnt5a/Dl1 1:1 for 14-21 days in aMEM 10\% FCS in presence of IL-7, SCF and Flt3 L cytokines. (b) Experimental design. OP9-Dl1-GFP cell lines were transduced with pRRL-SFFV-Wnt3a-tomato (DLW3A) or pRRL-SFFV-Wnt5a-Tomato (DLW5A) and selected by cell sorting on high GFP expression. Stem cells from E14 fetal liver cells were co-cultured with OP9-Dl1 as a control, OP9-DLW3A or OP9-DLW5A for 14 days in aMEM 10\% FCS in presence of same cytokines. (c) RTq-PCR analysis was performed to determine overexpression of Wnt3a (left bar), Wnt5a (middle bar) and Dl1 gene (right bar) in transduced OP9 cell lines. The levels of expression are normalized by ABL-2 expression and presented as fold induction relative to untransduced OP9 cell line. (d) The overexpression of Dl1 gene (gray bars), Wnt3a gene (white bars) and Wnt5a gene (black bars) in untransduced OP9DL1 cell line (left), OP9-DLW3A cell line (middle) and OP9-DLW5A (right) are shown. The levels of expression are normalized by ABL-2 expression and presented as fold induction relative to untransduced OP9 cell line. (e) Total fetal liver cells were co-cultured with OPg-WT/DL1: 1 as control (top row), OP9-Wnt5a/DL1:1 (middle row) or OPg-Wnt3a/DL1:1 (bottom row). Cells were harvested 4 days and 14 days after co-culture and were analyzed flow cytometric for DN stages of T-cell development. The plots are pre-gated for Thy1+ and LIN- markers. Lineage markers include CD3e, CD4, CD8a, CD11b, Gr1, B220, NK1.1 and Ter119. The percentage of each population is indicated. (f) Collective data of total experiments from (e) are depicted. Total fetal liver cells are co-cultured with OP9-WT/DL1: 1 as control (white bars) or with OP9-Wnt3a/DL11: 1 (Black bars). Cells were harvested at day 4 and day 14 of co-culture and were assessed by FACS for DN stages of T-cell development. The percentage of each stage is shown within Thy $1+$ Lin- population. Data are mean \pm S.D. of nine control and eight Wnt3a samples from three independent experiments. ${ }^{*} P<0.05$; ${ }^{\star \star} P<0.01$; ${ }^{* \star \star} P<0.001$ 
e
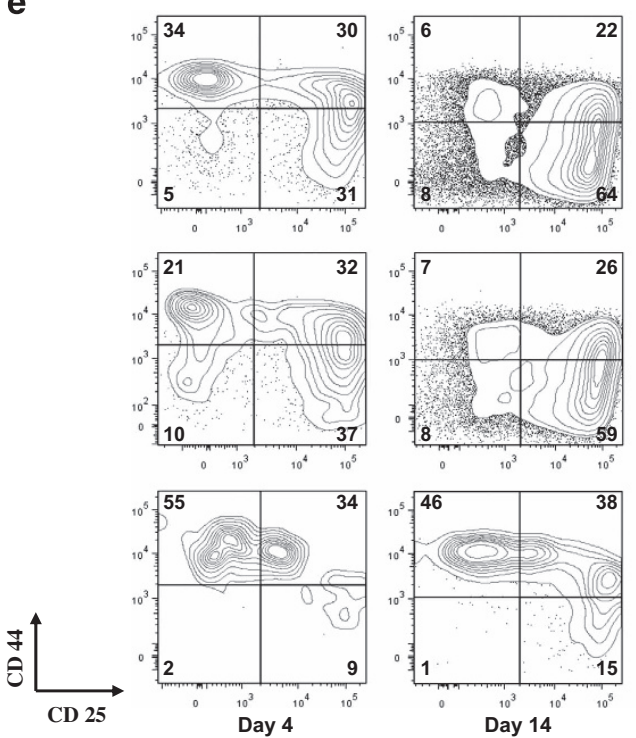

Pre gate: Thy1+ Lin-

$\mathbf{f}$

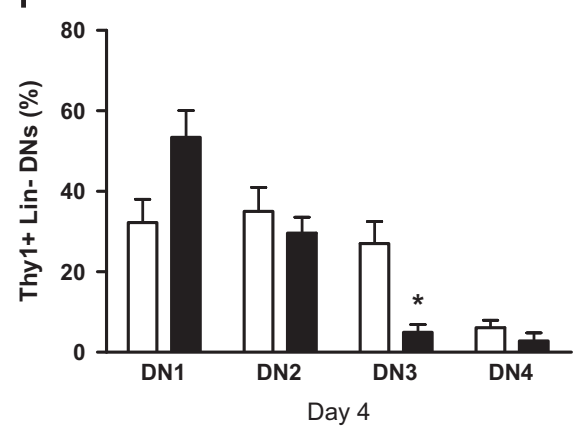

Figure 1 Continued

impaired T-cell development caused to an ISP block. ${ }^{24}$ Several loss-of-function and gain-of-function studies have targeted the core Wnt-mediator $\beta$-catenin in thymocytes. Conditional $\beta$-catenin deletion using Lck-Cre impaired $\beta$-selection of TCR, ${ }^{25}$ whereas $\beta$-catenin overexpression regulates positive selection and generation of SP CD4/ CD8. ${ }^{26}$ Inhibiting the interaction between $\beta$-catenin and Tcf1 also blocks the DN to DP transition. ${ }^{27}$ Wnt signaling is active at various stages of T-cell development but most predominantly at DN stages. Indeed, inhibiting Wnt signaling by using Dickkopf (DKK1) as Wnt sequestering molecule, blocks the development at the most immature DN1 stage. ${ }^{21}$ Finally, genetic proof that canonical Wnt signaling is crucial for normal T-cell development stems from complementation studies in which only the large form of Tcf1 that can interact with $\beta$-catenin and transduce Wnt signals was capable to restore T-cell development, whereas the short form that lack the $\beta$-catenin domain could not. ${ }^{28}$

On contrary, there are only a handful of studies focused on the role of non-canonical Wnt signaling in T-cell development. Liang et al. ${ }^{29}$ showed that Wnt5a deficiency protects against apoptosis in DP stage, but it was proposed to be irrelevant at early stages of T-cell development. Another series of studies
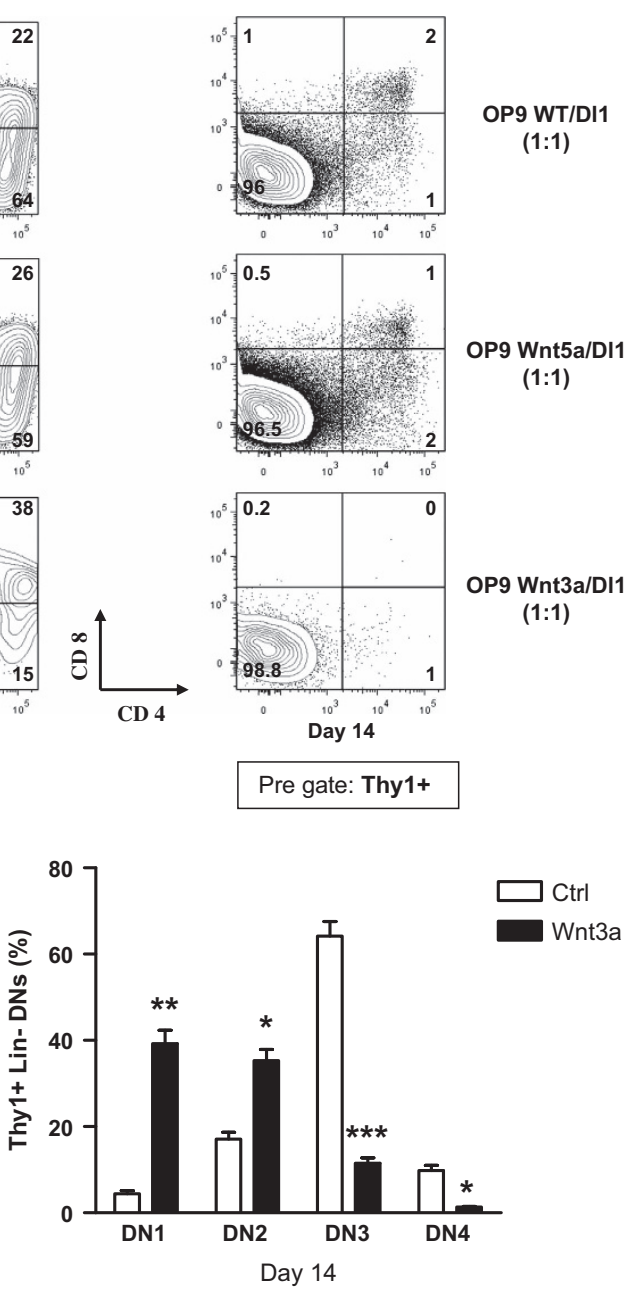

revealed that Wnt4 induces expansion of Lin- Sca1+ Kit+ (LSKs) in BM, which subsequently causes ETP expansion in thymus. ${ }^{30}$ Wnt4 regulates ETP expansion via a TEC-dependent mechanism. ${ }^{31}$ Whether Wnt4 functions as a canonical or noncanonical ligand is still debatable, in particular in gain-offunction studies in which thymopoiesis was increased. Perreault and colleagues showed that Wnt4 binds to Fzd6 and activates JNK kinase via PCP pathway, ${ }^{32}$ strongly suggesting that Wnt4 signals in a non-canonical fashion.

Loss-of-function approaches using $\beta$-catenin and $\gamma$-catenin have often not revealed thymic phenotypes, ${ }^{33}$ most likely because Wnt signaling is still present at appreciably levels in these models. ${ }^{34}$ In addition, during T-cell development canonical and non-canonical Wnt signaling have only been studied in isolation but not together. Here, we aimed to sideby-side compare the two prototypical canonical and noncanonical Wnt ligands, that is, Wnt3a (canonical) and Wnt5a (non-canonical).

\section{Results}

OP9-based in vitro assays for T-cell development. To study the role of canonical and non-canonical Wnt signaling 
during T-cell development in vitro, we generated two different OP9-based assays. First, we transduced OP9-WT cell line with Wnt3a and Wn5a constructs linked to an IRES-GFP cassette, mixed the transduced cell lines with the OP9-DI1 cell line in 1:1 ratio to support T-cell development (Figure 1a). Initially, we examined efficiency of the OP9 cell mixtures for support of T-cell development in comparison with OP9-DI1 cell line alone. The aim of mixing Wnt3a- and Wnt5aproducing OP9 cells with OP9-DL11 was (a) supporting T-cell development in contrasting situation of abundant Wnt3a vs Wnt5a (b) creating an culture system to study $T$ and $B$ lymphoid as well as myeloid development simultaneously. Although there was a slight delay in T-cell development at 14-21 days, the mixture could also efficiently support T-cell development up to the DP stages, whereas OP9-WT did not induce T-cell development (See Supplementary Figure 1).

We also generated another OP9-based assay in which we directly transduced OP9- DI1-GFP cell line with Wnt3a and Wnt5a-tomato constructs, and assessed in vitro T-cell development (Figure 1b). We quantified relative expression of Wnt3a, Wnt5a and DI1 using Q-PCR. Wnt3a had over 1000fold higher expression compared with OP9-WT, whereas Wnt5a had $\sim 500$-fold and DI1 remained to be expressed at levels over 700-fold (Figure 1c). In OP9-DLWnt3a-tomato (DLW3A) and OP9-DLWnt5a-tomato (DLW5A) Wnt3a and Wnt5a were expressed as high as in the OP9-Wnt3a-GFP and
OP9-Wnt5a-GFP, respectively, and DI1 expression was not altered compared with the OP9-DI1-GFP (Figure 1d).

Canonical Wnt3a overexpression blocks T-cell development at early stages, thereby favoring development of alternative lineages. We cultured fetal liver cells (as these provide a good source of both T-cell progenitors and stem cells) either with the mixture of OP9-WT/DI1 in 1:1 ratio as a control, or with OP9-Wnt3a/DI1 or OP9-Wnt5a/DI1 with the same ratio for 14 days. Wnt3a overexpression blocked T-cell development at the DN1 stage (Figures 1e and f).

The mixture of OP9-WT and OP9-DI1 provides a means to study development of $\mathrm{B}, \mathrm{T}, \mathrm{NK}$ and myeloid lineages simultaneously. ${ }^{35}$ DN1 and DN2 immature thymocytes have the potential to develop towards other lineages. Consistently, in the Wnt3a-overexpressing cultures, non T cells, such as B and myeloid cells developed more efficiently compared with the control (Figures $2 a$ and $b$ ). The difference was not only observed in proportion of each lineage, but also in the absolute numbers (Figure 2c).

Similar data were observed when Wnt3a and Wnt5a were expressed in the OP9-DI1 cells themselves (supplementary Figure 2). Therefore, we conclude that canonical Wnt3a signaling has the capacity to inhibit T-cell development at early DN2-DN3 stages, and to increase alternative (myeloid and B cell) development. Wnt5a overexpression in neither of assays

a
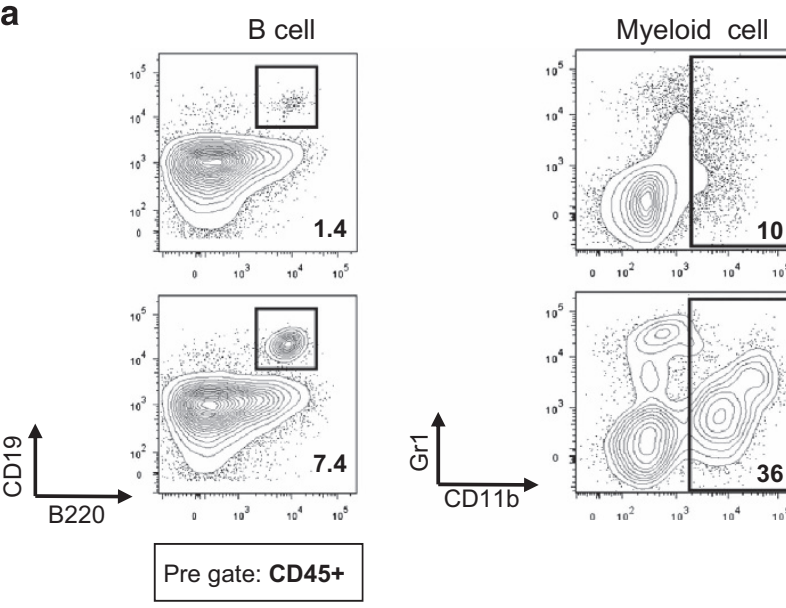

OP9 WT/DL
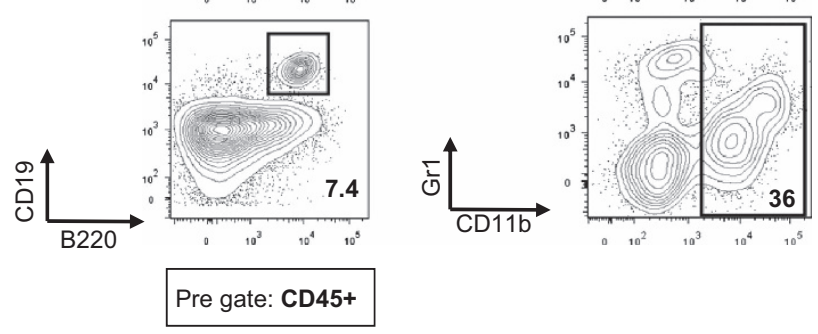

OP9 Wnt3a/DL
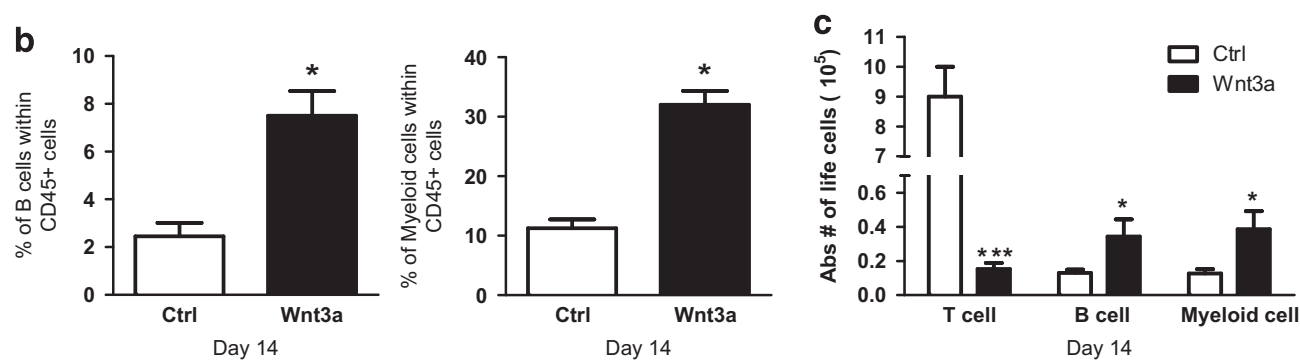

Figure 2 Wnt3a overexpression favors alternative lineages development. (a) Total fetal liver cells were co-cultured with OP9-WT/DL1:1 (top row) or with OP9-Wnt3a/ DL11: 1 (bottom row). Cells were harvested after 14 days of co-culture and were analyzed by FACS for B cells (B220 and CD19) and myeloid cells (CD11b and Gr1). The plots are pre-gated on CD45+ cells. Representative plots of two independent experiments are shown. (b) Collective data of all experiments are depicted. OP9-WT/DL (Ctrl) are depicted in white bars and OP9-Wn3a/DI (Wnt3a) in black bars. The left bar graphs present percentage of B cells (B220+ CD19+) within the CD45+ gate, and right bar graphs present percentage of myeloid cells (CD11b+Gr1+) within the CD45+ gate. (c) Absolute number of total CD45+ life cells after 14 days of co-culture are depicted. Data are mean \pm S.D. of six controls and five Wnt3a samples from two independent experiments. ${ }^{*} P<0.05 ;{ }^{* \star} P<0.01 ;{ }^{* * *} P<0.001$ 
a

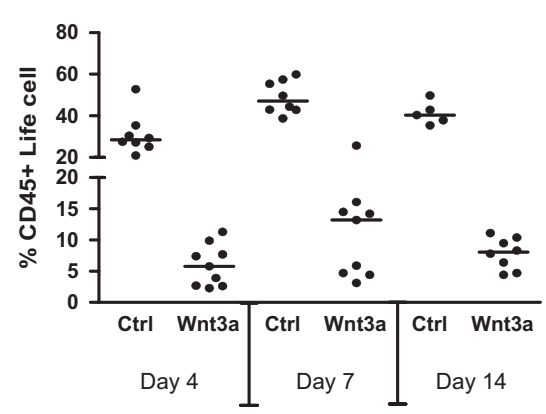

b

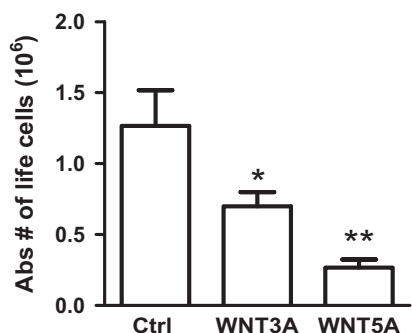

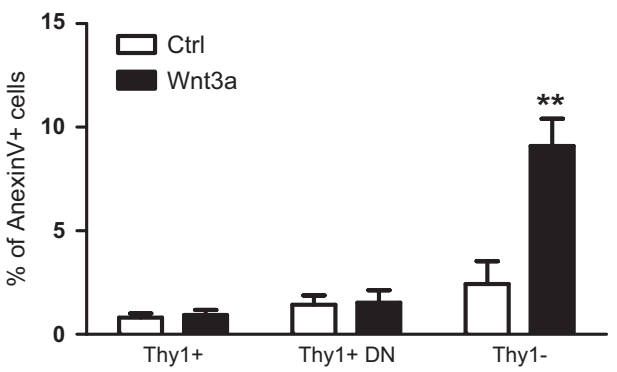

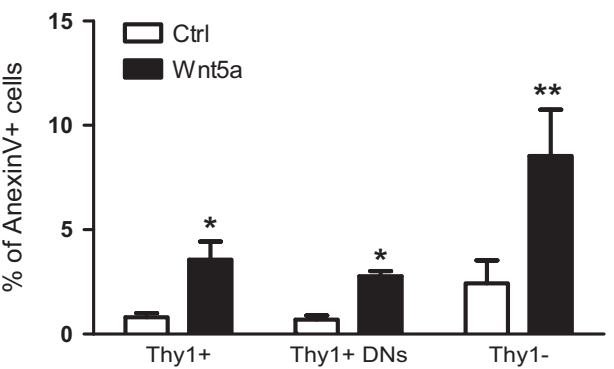

C

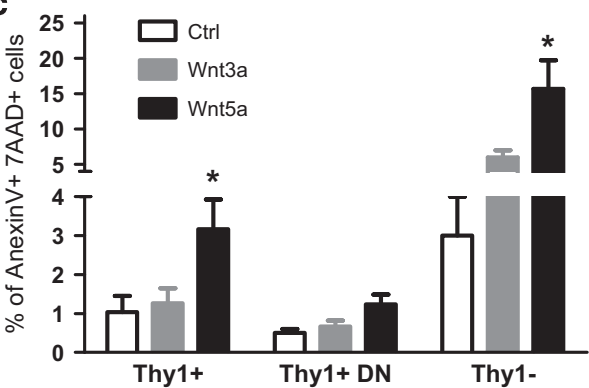

Figure 3 Wnt5a overexpression results in apoptosis in developing thymocytes. (a) Total fetal liver cells were co-cultured with OP9-WT/DL1:1 (Ctrl) or with OP9-Wnt3a/ DL1 : 1 (Wnt3a) or with OP Wnt5a/Dl1 (Wnt5a). In the left graph, the percentage of total CD45+ life cells were assessed by FACS after 4 days, 7 days and 14 days of co-culture. The averages are indicated by a dash. Each dot represents one mouse. In the right graph, the percentage of AnexinV+ apoptotic cells is shown in specified populations after 14 days of co-culture with OPg-WT/DL (white bars) or with OP9-Wnt3a/DL (black bars). Error bars represent mean \pm S.D. from two independent experiments (each in triplicates). (b) In the left graph, the absolute number of life cells is shown after 14 days of co-culture. Error bars represent mean \pm S.D. from two independent experiments (each in triplicates). In the right graph, the percentage of AnexinV+ apoptotic cells is shown in specified populations after 14 days of co-culture with OPg-WT/DL (white bars) or with OPg$\mathrm{Wnt5a/DL}$ (black bars). Error bars represent mean \pm S.D. from two independent experiments each in triplicates. (c) Percentage of AnexinV+AAD7+ cells representing dead cells in the culture gated on tall thymocytes, DN thymocytes and non-T lineage cells in thymic cultures with Wnt3a or Wnt5a expressed in OPg-DL1 cells. ${ }^{*} P<0.05 ;{ }^{* *} P<0.01$; ${ }^{* * *} P<0.001$

did show any phenotypic difference regarding T-cell development (data not shown).

Wnt5a overexpression results in increased apoptosis in developing thymocytes, whereas Wnt3a does not. Further analysis revealed that total percentage of lymphocytes was around fourfold lower in the Wnt3a-overexpressing group at various time points after co-culture $(4,7$ and 14 days) (Figure 3a). This could be caused by increased apoptosis in the Wnt3a-expressing cultures. We performed apoptosis assays by using AnexinV and 7AAD in combination with the Thy1 marker to separate T cells from non-T cells. In the Wnt3a-overexpressing cultures total Thy1+thymocytes and specifically DN thymocytes were not undergoing any a significant level of apoptosis (Figure 3a). There is an increase in apoptosis in non $\mathrm{T}$ cells, yet not to the extent that non
$T$ cells would decrease in numbers in comparison with thymocytes (see Figures $2 b$ and $c$ ). Thus, we concluded that inhibition of differentiation toward $\mathrm{T}$ lineage due to Wnt3a overexpression causes low cellularity in this culture.

Although the Wnt5a-overexpressing cultures did not show any phenotypic differences compared with the controls, the absolute numbers were around three- to fivefold lower (Figure $3 b$ ). Lack of $\mathrm{Wnt5a}$ promotes $\mathrm{Bcl}-2$ expression and inhibits apoptosis of DP thymocytes. ${ }^{29}$ Our analysis showed that both Thy $1+$ and Thy $1-$ co-cultured cells were undergoing more apoptosis. Thus, this gain-of-function approach showing more apoptosis is consistent with the loss-of-function Wnt5a experiments reported before. The effect of apoptosis in thymocytes (DN and Thy1+) by Wnt5a was much stronger than Wnt3a, which was similar to controls. Interestingly, for non $\mathrm{T}$ cells, similarly high apoptosis was found. The strong 

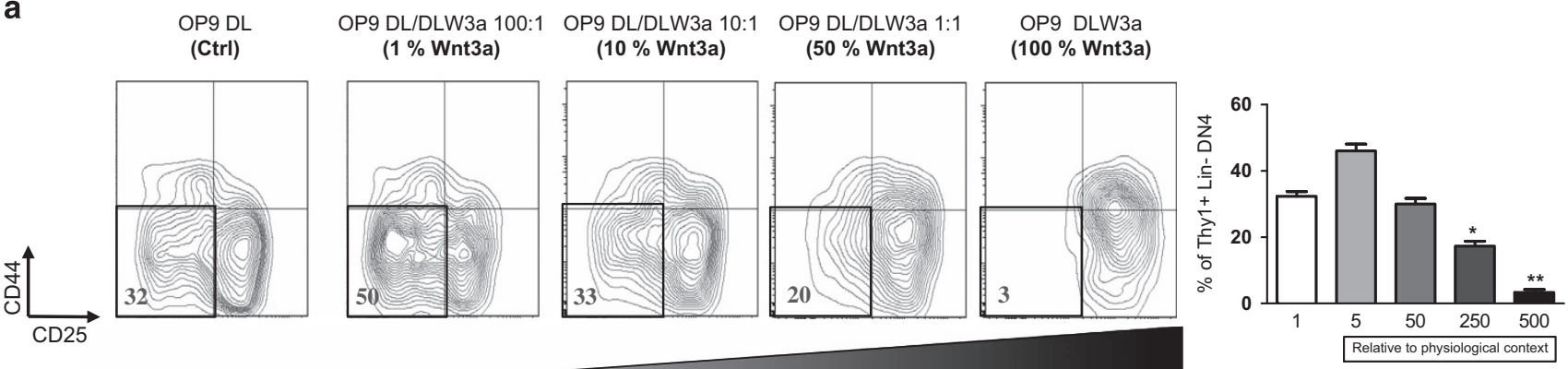

Wnt3a dosage

b

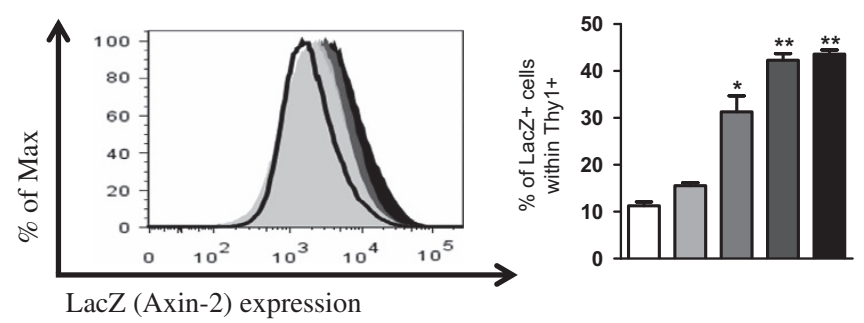

Figure 4 Optimal dosage of canonical Wnt signaling accelerates T-cell development. (a) Total FL cells were co-cultured for 14 days with OP9-DL1, or different ratios of OP9DLW3A/ OP9-D11 mixture as indicated. Cells were then harvested and were analyzed by FACS for DN stages of T-cell development. The percentage of CD44 - CD25 - DN4 is indicated. The plots are pre-gated on Thy1+ LIN- markers. Error bars represent mean \pm S.D. of one independent experiment in triplicates. Below the bar graphs Wnt3a gene overexpression relative to the physiological levels are indicated. (b) Total FL cells from Axin2 LacZ (wnt reporter mice) were co-cultured with OP9-DL1 and different ratios of OP9DLW3A as previously indicated. Cells were harvested and $\beta$-galactosidase (LacZ) activity in Thy1+ cells was measured. Quantification of the mean fluorescence intensity (MFI) of Thy1+ cells is shown (left). Quantification of the frequency of LacZ+ cells is shown (right). Littermate mice not carrying the reporter transgene (Axin2 $+/+$ ) were used to define the LacZ- population. Data represent four Axin2 $+/-$ mice and two Axin2 $+/+$ control mice. Error bars represent mean \pm S.D. ${ }^{*} P<0.05 ;{ }^{* *} P<0.01 ;{ }^{* * *} P<0.001$

effects of Wnt5a on cell death are also reflected in the strong increase in 7AAD+AnnexinV+ DP cells (Figure 3c).

Optimal dosage of Wnt3a signaling accelerates T-cell development. Gene expression analysis revealed that Wnt3a was very highly expressed in our transduced OP9 cells (Figures $1 \mathrm{c}$ and d). This is 500 -fold higher than the physiological level, for example, as found in fetal thymus, ${ }^{21}$ which we used as comparison. We have previously shown that canonical Wnt signaling functions in a dosagedependent fashion during HSC reconstitution and T-cell development using Apc hypomorphic models. ${ }^{19}$ We hypothesized that the same would hold true with the Wnt3a gain-offunction model. We modified the Wnt3a concentration in the culture by serially mixing OP9-DL with OP9-DLW3a at various ratios.

After 14 days of co-culture, the majority of cells developed into DN3 and DN4 with $32 \%$ of DN4 thymocytes. Interestingly, the co-cultured cells with 1\% DLW3A (which has fivefold higher overexpression relative to the physiological level, supplementary Figure 3 ), showed an accelerated T-cell development with $50 \%$ DN4 thymocytes development. However, T-cell development was inhibited again by increasing the concentration of DLW3A (10\% and 50\% Wnt3a), and was completely blocked at the DN3 stage with 100\% OP9-DLW3A alone (Figure 4a).

To determine the Wnt signaling activity, we performed the same experiment using Axin2 ${ }^{\text {LacZ }}$ heterozygous reporter cells, a well-established Wnt reporter mouse model. ${ }^{36}$ Phenotypic analysis of the co-cultured cells exhibited similar T-cell development potential at different dosages of Wnt3a (data not shown). Importantly, the actual Wnt signaling activity of total Thy $1+$ cells correlated with the increasing concentration of Wnt3a (Figure 4b). Therefore, our data suggest that Wnt3a canonical Wnt signaling functions in a dosage-dependent fashion, in accordance with the differential Wnt signaling activity of the cells.

Wnt3a overexpression enhances B lymphopoiesis and Wnt5a overexpression augments myelopoiesis in vivo. To study the role of Wnt3a and Wnt5a signaling in vivo we carried out reconstitution assays in which we sorted CD45.2 LSK cells from fetal liver, transduced them with lentiviral vectors encoding Wnt3a, Wnt5a in combination with GFP, and transplanted them into irradiated CD45.1 B6-recipient mice (Figure 5a). At week 16 post transplantation we analyzed spleen, thymus and BM of the recipients. In the spleens of Wnt3a-overexpressing mice the percentage of B220+ CD19+ B cells was around twofold higher compared with the control mice within the GFP+ transduced compartment. In contrast, Wnt5a-overexpressing mice had around twofold higher percentage of CD11b+Gr1+ myeloid cells relative to the control. Therefore, the ratio of $\mathrm{B}$ cells versus myeloid cells was in favor of $B$ cells in the Wnt3a group, and in favor of myeloid cells in the Wnt5a group (Figures $5 \mathrm{~b}$ and $\mathrm{c}$ ).

In the $\mathrm{BM}$, the ratio of $\mathrm{B}$ cells versus myeloid cells was around threefold lower in the Wnt5a group, whereas there was no statistically significant difference between the control and Wnt3a group. MPPs (LSK Flt3+) were around 


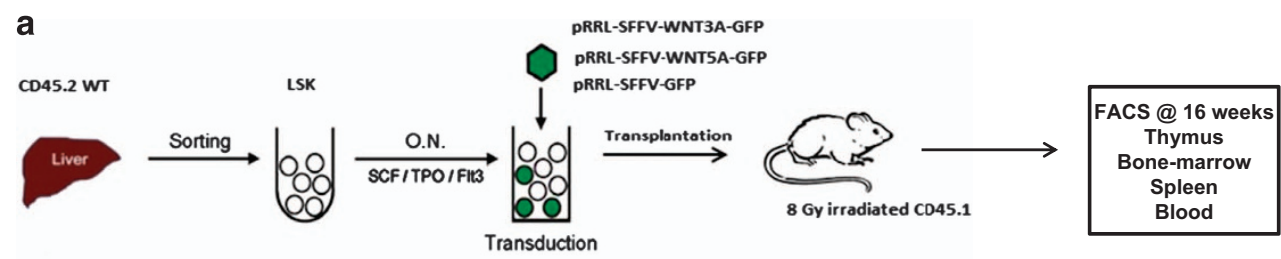

b

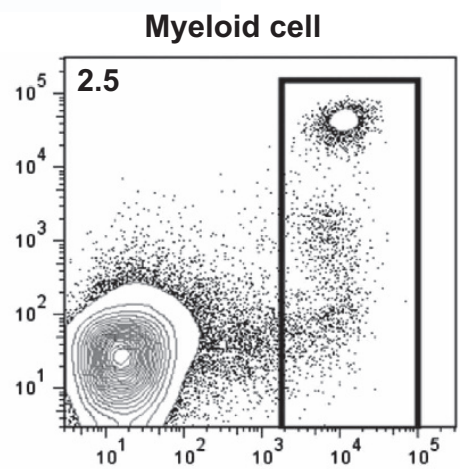

Ctrl
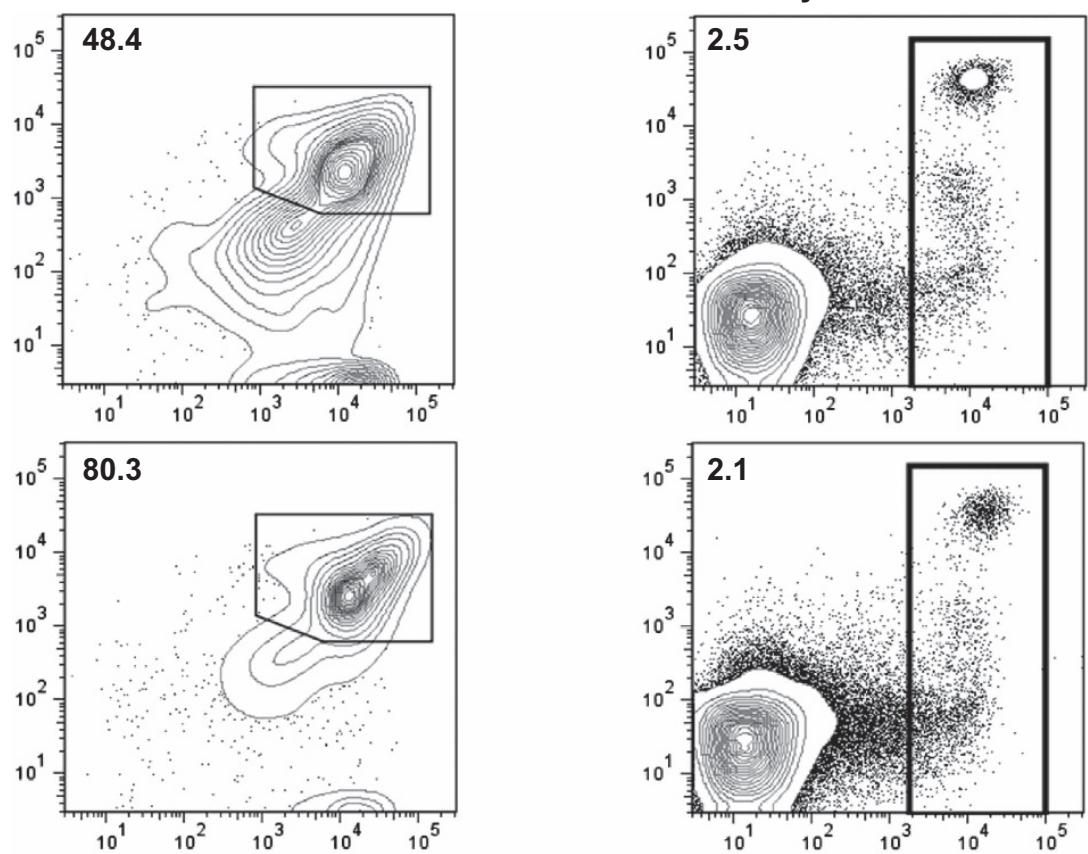

Wnt3a
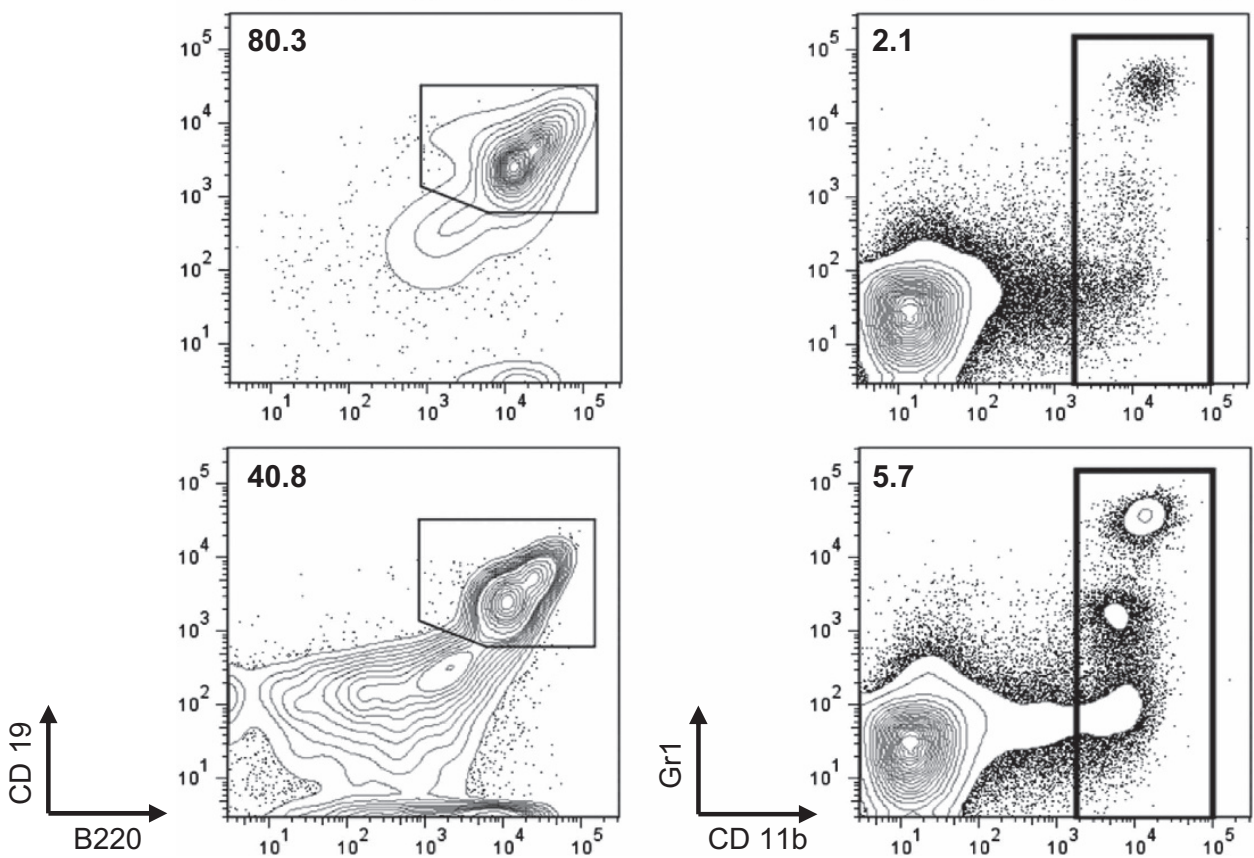

Wnt5a
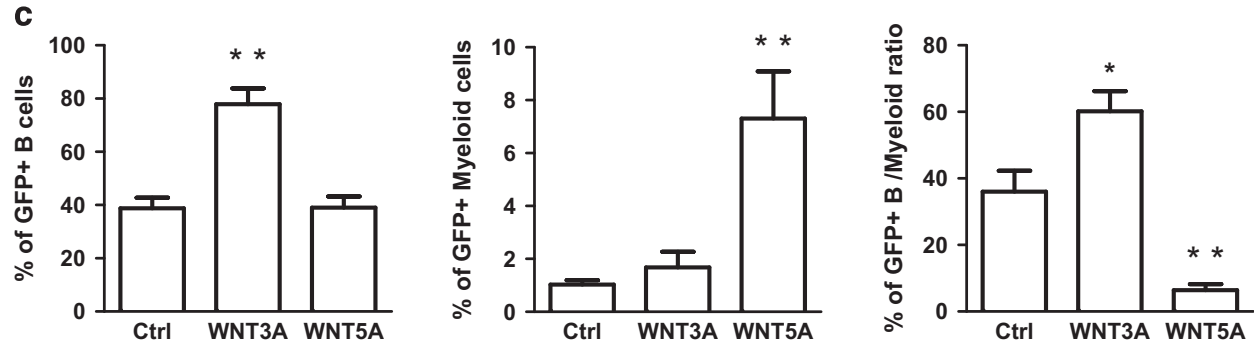

Figure 5 Wnt3a overexpression enhances lymphopoiesis, whereas Wnt5a overexpression augments myelopoiesis in vivo. (a) Experimental design. Lin- Sca1+ Kit+ (LSK) cells were sorted from E14 WT FL and were stimulated overnight in medium with SCF, TPO and Flt3-L cytokines. Next day, the cells were transduced with pRRL-SFFV-GFP (Ctrl), pRRL-SFFV-Wnt3a-GFP (Wnt3a) or pRRL-SFFV-Wnt5a-GFP (Wnt5a). Bulk of transduced cells were transplanted intravenously into CD45.1 8 Gy irradiated recipients. At week 16 post transplantation, the mice were killed and blood, spleen, BM and thymus were harvested and were assessed by FACS. Each group consists of five mice. (b) Representative FACS plots of $B$ cell (B220+ CD19+) and myeloid cells $(C D 11 b+G 1+)$ in the spleen of a recipient mouse 16 weeks after transplantation. The cells are pre-gated on CD45.2+ CD45.1 - and GFP+. The numbers indicate percentage of cells within the gate. (c) Collective data represent the percentage of GFP+ B cells (left graph), myeloid cells (middle graph), and the ratio of $B$ cells versus myeloid cells in the spleen of each group. Data are mean \pm S.D. of five mice per group. ${ }^{\star} P<0.05 ;{ }^{* \star} P<0.01 ;{ }^{* \star *} P<0.001$ 

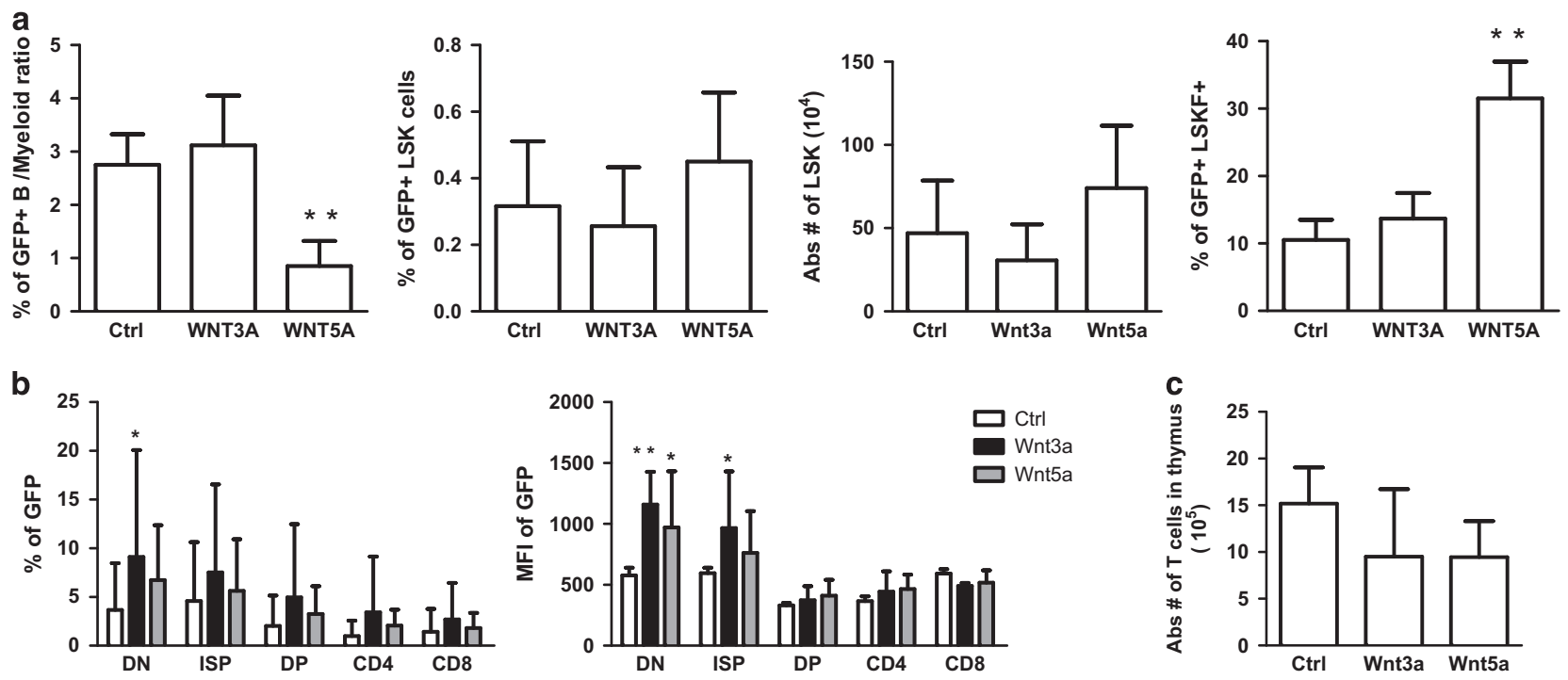

Figure 6 Wnt3a overexpression blocks T-cell development at early stages in the thymus. (a) At week 16 post transplantation, BM and Thymus are harvested and assessed by FACS Collective data depict the ratio of GFP+ B cells versus myeloid cells (Left), percentage and absolute number of LSKs (Middle), and percentage of LSK Flt3+ ${ }^{46}$ in the BM. Data are mean \pm S.D. of five mice per group (right). (b) Collective data show percentage (left), or mean fluorescent intensity (MFI) (right) of GFP within each T-cell developmental stage for Ctrl group (White bar), Wnt3a group (Black bars) and Wnt5a group (gray bars). Data are mean \pm S.D. of five mice per group. (c) Bar graph depict absolute number of total thymus (thymic cellularity) within each group. Data are mean \pm S.D. of five mice per group. ${ }^{*} P<0.05 ;{ }^{* *} P<0.01 ;{ }^{* * *} P<0.001$

threefold higher in the Wnt5a group compared with the control (Figure 6a). In the thymus, T-cell development was clearly blocked at early stages in the transduced compartment of the Wnt3a group, and to some extend with Wnt5a (as characterized by higher percentage and MFI of GFP in DN and ISP stages). However, the blocks did not affect the absolute number of mature $T$ cells or total thymic cellularity (Figures $6 b$ and $c$ ). Thus, Wnt3a overexpression induces B lymphopoiesis in spleen and BM whereas Wnt5a overexpression induces increased myelopoiesis in these organs.

\section{Discussion}

Canonical Wnt signaling has a well-established role in T-cell development in the thymus; yet only a few reports deal with non-canonical Wnt signaling. A side-by-side comparison of the effects of these interacting pathways has not been performed, in contrast to for instance B-cell development ${ }^{20}$ and HSC biology. ${ }^{37}$ We therefore set out to compare the prototypical canonical Wnt ligand Wnt3a with the prototypical non-canonical Wnt ligand Wnt5a. We demonstrated that the induction of canonical Wnt signaling via Wnt3a is first, important for T-cell development, and second functions in dosage-dependent fashion. Although intermediate-to-low doses of canonical Wnt signaling is beneficial for thymopoiesis, higher doses support B lymphopoiesis in vivo. On the other hand, Wnt5a non-canonical Wnt signaling induces myelopoiesis in vivo and it does not appear to function in a strict dosage-dependent fashion. Moreover, Wnt5a signaling induces apoptosis in developing thymocytes, in line with the diminished apoptosis observed in Wnt5a-deficient thymi.

Previous studies in our laboratory and many others revealed that canonical Wnt signaling is crucial for T-cell development, and it functions in a dosage-dependent fashion. ${ }^{19}$ In the current study we used Wnt3a, a natural ligand of canonical Wnt signaling, and we obtained similar data. This shows that Wnt3a triggers canonical Wnt signaling via the $\beta$-catenin and TCF/LEF-dependent pathway in the thymus, ${ }^{34}$ and that it is possible to modulate canonical Wnt signaling via differential concentration of Wnt3a physiologically. It is very likely that in the thymus, developing thymocytes are exposed to different types and concentrations of Wnt ligands. It is likely that thymocytes express different FZD receptors with various binding affinity to the existing Wnt proteins within the thymic microenvironment. Previous Q-PCR data suggest that this might be the case, ${ }^{21}$ although experimental proof awaits the development of specific antibodies for each Frizzled receptor suitable for flow cytometry. As a result, developing thymocytes would undergo different levels of Wnt signaling owing to the accumulation of different amounts of $\beta$-catenin proteins in the cytoplasm.

Another possibility is that the interaction of canonical and non-canonical Wnt signaling might be important for control of $\beta$-catenin dosage in the cytoplasm. Sugimura et al. ${ }^{37}$ elegantly described a situation where canonical and non-canonical Wnt signaling interact with each other in the hematopoietic system. Non-canonical Wht maintains quiescent long-term HSCs through Flamingo and Frizzled 8 receptor on HSCs. Under stress, non-canonical Wnt is attenuated and canonical Wnt is enhanced, which results in the activation of HSC. The same might be true during T-cell development in the thymus under stress, which could be a fascinating issue for future studies.

Previously, Malhorta et al..20 used a similar OP9-based Wnt3a/Wnt5 gain-of-function approach to study B lymphopoiesis. There are several differences between these two studies. (i) Their study is restricted to lympho-hematopoiesis of the BM and not thymopoiesis in the thymus. ${ }^{34}$ Their study was 
confined to in vitro work using FACS-purified stem cells. Importantly, using a $\beta$-catenin overexpression approach, Kincade and coworkers ${ }^{38}$ showed that committed B-cell progenitors gained myeloid lineage potential. Although we did not observe such phenomena in the T-cell lineage, Wnt3a clearly could maintain cells in an immature stage, at which thymocytes can still develop into alternative lineages. Thus, despite these differences, both studies suggest distinctive roles of Wnt family proteins during hematopoiesis and lymphopoiesis, and Wnt3a inhibits progenitor cell differentiation. However, the effect of Wnt5a on B-cell development is controversial. Malhorta et al. ${ }^{39}$ showed that it induces B lymphopoiesis, whereas Liang et al. showed inhibition of B-cell proliferation. We did not observe any effect of Wnt5a on B-cell development even at higher doses (data not shown) which could be due to the difference in timing, source of stem cells or concentration of Wnt proteins.

Khoo et al. ${ }^{40}$ have demonstrated that human aged HSCs have a reduced canonical Wnt signaling activity, and as a result impaired or delayed T-cell development, which is restricted to the $\mathrm{T}$-cell progenitors, indicating the significance of Wnt signaling in human T-cell development during senescence. The notion that non-canonical Wnt signaling mimics murine HSC ageing has been put forward by Florian et $a l^{41}$ They reported that a shift from canonical to noncanonical Wnt signaling occurs during HSC ageing. Wnt5a treatment of young HSCs induced ageing associated stem cell apolarity, and an lymphoid to myeloid differentiation skewing, which is observed normally during ageing. We performed similar experiments in which we transduced HSC with Wnt3a and Wnt5a, rather than ex vivo treatment. Similarly, myelopoiesis was enhanced in Wnt5a-overexpressing HSC, and B lymphopoiesis in Wnt3a-overexpressing HSC (Figures 5 and 6). Therefore, Wnt3a treatment of stem cells before transplantation could be considered a promising approach to improve lymphopoiesis.

A series of studies in the laboratory of Perreault and coworkers $^{30-32}$ suggest that Wnt4 is a non-canonical Wnt ligand, enhances MPP expansion in the BM and ETP proliferation in the thymus, which results in increased thymic cellularity. We have also shown that Wnt5a overexpression induces MPP expansion, and DN expansion in thymus (Figure 6). However, this did not affect the total cellularity of the organs. This suggests specific roles of various Wnt family members during different stages of thymopoiesis, probably due to their differential expression throughout the thymus and/ or differential responsiveness of developing thymocytes. For instance, Wnt4 has been proposed to function as a canonical Wnt in inducing FoxN1 expression in TEC, ${ }^{42}$ but seems to act as a non-canonical Wnt in studies aimed at improving thymic reconstitution from hematopoietic rather than thymic stromal cells. $^{30}$

Previous studies indicate that deregulation of Wnt signaling occurs in leukemia. ${ }^{43}$ We have also shown that deregulation of Wnt signaling due to the absence of Tcf1, induces lymphomas in mice. ${ }^{44}$ Independent of our study, Yu et al. ${ }^{11}$ also reported similar results and showed similarities of Tcf1 lymphomas with human ETP-ALL cases. In addition, Martins et al. ${ }^{45}$ recently suggested that natural cell competition between young and old thymic progenitors is crucial for inhibition of T-ALL development. Therefore, thymic progenitor fitness is necessary for normal T-cell development. Our gain-of-function Wnt3a model preserves thymocytes in an immature state without inducing any malignancy. It is therefore intriguing to speculate that canonical Wnt signaling may be involved in regulating stemness of thymic stem cells.

Concluding, our work and that of others referred to above show discrete effects of Wnt3a and Wnt5a treatment on hematopoietic cells, both in vitro and in vivo. These attempts might lead to application of Wnt ligands as therapeutic candidates to improve HSC repopulation and T-cell reconstitution after SCT. However, the challenge and focus of future studies should be on determining the 'right concentration' of Wnt proteins to avoid deregulated Wnt signaling.

\section{Materials and Methods}

Some methods are described in the supplementary data.

Lentiviral production and transduction. Wnt3a and Wnt5a gene transfer plasmids individually cloned into the multiple cloning sites of pRRLSFFV-IRES-GFP lentiviral vector by restriction digestion and ligation reactions. $293 \mathrm{~T}$ cells were transiently transfected with either the genes transfer or empty control constructs together with helper plasmids using X-TremeGENE9 transfection reagent (Roche, Basel, Switzerland). Virus containing supernatants were harvested $20 \mathrm{~h}$ and $40 \mathrm{~h}$ after transfection in Iscove's Modified Dulbecco's Medium supplemented with $10 \%$ fetal bovine serum, L-glutamin, $100 \mathrm{U} / \mathrm{ml}$ penicillin and $100 \mathrm{mg} / \mathrm{ml}$ streptomycin and used immediately for transduction, or stored at $-80^{\circ} \mathrm{C}$ for later use.

For transduction of OP9 stromal cells, 150000 OP9-WT or OP9DL1 cells were seeded into a well of six-well plates with alpha MEM (Lonza, Verviers, Belgium) supplemented with $20 \%$ FCS-HI, L-glutamin and penicillin/streptomycin. The following day, OP9 cells were transduced with fresh or frozen viral supernatant containing $4 \mu \mathrm{g} / \mathrm{ml}$ proteamine sulfate (Sigma-Aldrich, St. Louis, MO, USA). After few days of culture transduced GFP+ cells were sorted, and stable OP9-pRRL-GFP (empty vector transduced), OP9-(DL1)- W3A (Wnt3a-transduced) and OP9-(DL1)-W5A (Wnt5atransduced) cell lines were generated. Overexpression of the genes were then confirmed by Q-PCR gene analysis. The overexpression of DL1 gene was not altered in the transduced cell lines compared with untransduced or transduced with empty vector.

Coculture of fetal liver cells with OP9 cell lines. For different experiments various conditions of OP9 co-cultures were used as follows: OPg-WT, OP9-DL1-GFP, OP9-WT/DL1 (1: 1), OP9-DLW3A, OP9-DLW5A, OP9-DLW3A/DL1 (1:1), OP9-DLW3A/DL1 (1:10) and OP9-DLW3A/DL1 (1:100). In all conditions 50000 total fetal liver cells were cultured on confluent layers of OP9 cells, with AlphaMEM 10\% FCS containing $50 \mathrm{ng} / \mathrm{ml} \mathrm{rmSCF}, 10 \mathrm{ng} / \mathrm{ml} \mathrm{rmFlt3L}$ and $10 \mathrm{ng} / \mathrm{ml}$ rmlL-7 (all cytokines from R\&D systems, Minneapolis, MN, USA) in a well of 24wells plate. For different purposes, cells were harvested after $6 \mathrm{~h}, 24 \mathrm{~h}, 3,7$ or 14 days of culture and stained for flow cytometric analysis.

In vivo transplantation assay. Transplantation assays were performed with the CD45.1/CD45.2 system. LSK cells were sorted from CD45.2 WT fetal liver mice, overnight stimulated in stemspan in presence of Flt3-L $(50 \mathrm{ng} / \mathrm{ml})$, TPO $(10 \mathrm{ng} / \mathrm{ml})$ and SCF $(100 \mathrm{ng} / \mathrm{ml})$. Next day, sorted LSKs were transduced by means of Retronectin (Takara Bio Inc., Kusatsu, Japan) with SFFV-IRES-GFP or SFFVWnt3a-IRES-GFP or SFFV-Wnt5a-IRES-GFP. The viral supernatants were titrated in advance to obtain equal transduction efficiency $(\sim 50 \%)$. One day after transduction $5 \times 10^{3}$ bulk transduced LSK cells were transplanted intravenously into lethally irradiated (8 Gy) CD45.1 (9-12 weeks) mice together with $5 \times 10^{5}$ CD45.1 spleen support cells. Chimeras was analyzed at 4,8 and 12 weeks after transplantation in peripheral blood, and mice were killed for analysis at 16 weeks post transplantation. Mice were considered repopulated when $>1 \%$ multilineage CD45.2 cells could be detected in nucleated peripheral blood cells 3 months after transplantation.

\section{Conflict of Interest}

The authors declare no conflict of interest. 
Acknowledgements. This work was supported by a TOP grant from The Netherlands Organization for Health Research and Development, ZonMw Project 4000812-98-09050.

1. Morrison SJ, Uchida N, Weissman IL. The biology of hematopoietic stem cells. Annu Rev Cell Dev Biol 1995; 11: 35-71.

2. Adams GB, Scadden DT. The hematopoietic stem cell in its place. Nat Immunol 2006; 7: 333-337.

3. Kondo M, Scherer DC, King AG, Manz MG, Weissman IL. Lymphocyte development from hematopoietic stem cells. Curr Opin Gene Dev 2001; 11: 520-526.

4. Kondo M, Wagers AJ, Manz MG, Prohaska SS, Scherer DC, Beilhack GF et al. Biology of hematopoietic stem cells and progenitors: implications for clinical application. Annu Rev Immunol 2003; 21: 759-806.

5. Zlotoff DA, Bhandoola A. Hematopoietic progenitor migration to the adult thymus. Ann NY Acad Sci 2011; 1217: 122-138.

6. Staal FJ, Weerkamp F, Langerak AW, Hendriks RW, Clevers HC. Transcriptional control of $t$ lymphocyte differentiation. Stem Cells 2001; 19: 165-179.

7. Rothenberg EV, Moore JE, Yui MA. Launching the T-cell-lineage developmental programme. Nat Rev Immunol 2008; 8: 9-21.

8. Staal FJ, Clevers HC. Wnt signaling in the thymus. Curr Opin Immunol 2003; 15: 204-208.

9. Staal FJ, Luis TC, Tiemessen MM. WNT signalling in the immune system: WNT is spreading its wings. Nat Rev Immunol 2008; 8: 581-593.

10. Staal FJ, Meeldijk J, Moerer P, Jay $P$, van de Weerdt BC, Vainio $S$ et al. Wnt signaling is required for thymocyte development and activates Tcf-1 mediated transcription. Eur $\mathrm{J}$ Immunol 2001; 31: 285-293.

11. Yu S, Zhou X, Steinke FC, Liu C, Chen SC, Zagorodna $O$ et al. The TCF-1 and LEF-1 transcription factors have cooperative and opposing roles in $T$ cell development and malignancy. Immunity 2012; 37: 813-826.

12. Dik WA, Pike-Overzet K, Weerkamp F, de Ridder D, de Haas EF, Baert MR et al. New insights on human $T$ cell development by quantitative $T$ cell receptor gene rearrangement studies and gene expression profiling. J Exp Med 2005; 201: 1715-1723.

13. Taghon T, Yui MA, Pant R, Diamond RA, Rothenberg EV. Developmental and molecular characterization of emerging beta- and gammadelta-selected pre- $T$ cells in the adult mouse thymus. Immunity 2006; 24: 53-64.

14. Yui MA, Feng N, Rothenberg EV. Fine-scale staging of $\mathrm{T}$ cell lineage commitment in adult mouse thymus. J Immunol 2010; 185: 284-293.

15. Anderson G, Jenkinson WE, Jones T, Parnell SM, Kinsella FA, White AJ et al. Establishment and functioning of intrathymic microenvironments. Immunol Rev 2006; 209: 10-27.

16. Petrie HT, Zuniga-Pflucker JC. Zoned out: functional mapping of stromal signaling microenvironments in the thymus. Annu Rev Immunol 2007; 25: 649-679.

17. Alves NL, Huntington ND, Mention JJ, Richard-Le Goff O, Di Santo JP. Cutting Edge: a thymocyte-thymic epithelial cell cross-talk dynamically regulates intrathymic IL-7 expression in vivo. J Immunol 2010; 184: 5949-5953.

18. Clevers H, Nusse R. Wnt/beta-catenin signaling and disease. Cell 2012; 149: 1192-1205.

19. Luis TC, Naber BA, Roozen PP, Brugman MH, de Haas EF, Ghazvini M et al. Canonical wnt signaling regulates hematopoiesis in a dosage-dependent fashion. Cell Stem Cell 2011; 9: 345-356.

20. Malhotra S, Baba Y, Garrett KP, Staal FJ, Gerstein R, Kincade PW. Contrasting responses of lymphoid progenitors to canonical and noncanonical Wnt signals. J Immunol 2008; 181: 3955-3964.

21. Weerkamp F, Baert MR, Naber BA, Koster EE, de Haas EF, Atkuri KR et al. Wnt signaling in the thymus is regulated by differential expression of intracellular signaling molecules. Proc Natl Acad Sci USA 2006; 103: 3322-3326.

22. Schilham MW, Wilson A, Moerer P, Benaissa-Trouw BJ, Cumano A, Clevers HC. Critical involvement of Tcf-1 in expansion of thymocytes. J Immunol 1998; 161: 3984-3991.

23. Okamura RM, Sigvardsson M, Galceran J, Verbeek S, Clevers H, Grosschedl R. Redundant regulation of $\mathrm{T}$ cell differentiation and TCRalpha gene expression by the transcription factors LEF-1 and TCF-1. Immunity 1998; 8: 11-20.

24. Luis TC, Weerkamp F, Naber BA, Naber BA, Baert MR, de Haas EF et al. Wnt3a deficiency irreversibly impairs hematopoietic stem cell self-renewal and leads to defects in progenitor cell differentiation. Blood 2009; 113: 546-554.

25. Xu Y, Banerjee D, Huelsken J, Birchmeier W, Sen JM. Deletion of beta-catenin impairs T cell development. Nat Immunol 2003; 4: 1177-1182.

26. Mulroy $T, X_{u} Y$, Sen JM. beta-Catenin expression enhances generation of mature thymocytes. Int Immunol 2003; 15: 1485-1494.
27. Pongracz JE, Parnell SM, Jones T, Anderson G, Jenkinson EJ. Overexpression of ICAT highlights a role for catenin-mediated canonical Wnt signalling in early $T$ cell development. Eur J Immunol 2006; 36: 2376-2383.

28. Ioannidis V, Beermann F, Clevers H, Held W. The beta-catenin-TCF-1 pathway ensures CD4(+)CD8(+) thymocyte survival. Nat Immunol 2001; 2: 691-697.

29. Liang $\mathrm{H}$, Coles AH, Zhu Z, Zayas J, Jurecic R, Kang J et al. Noncanonical Wnt signaling promotes apoptosis in thymocyte development. J Exp Med 2007; 204: 3077-3084.

30. Louis I, Heinonen KM, Chagraoui J, Vainio S, Sauvageau G, Perreault C. The signaling protein Wnt4 enhances thymopoiesis and expands multipotent hematopoietic progenitors through beta-catenin-independent signaling. Immunity 2008; 29: 57-67.

31. Heinonen KM, Vanegas JR, Brochu S, Shan J, Vainio SJ, Perreault C. Wnt4 regulates thymic cellularity through the expansion of thymic epithelial cells and early thymic progenitors. Blood 2011; 118: 5163-5173.

32. Heinonen KM, Vanegas JR, Lew D, KrosI J, Perreault C. Wnt4 enhances murine hematopoietic progenitor cell expansion through a planar cell polarity-like pathway. PloS One 2011; 6: e19279.

33. Jeannet G, Scheller M, Scarpellino L, Duboux S, Gardiol N, Back J et al. Long-term, multilineage hematopoiesis occurs in the combined absence of beta-catenin and gammacatenin. Blood 2008; 111: 142-149.

34. Luis TC, Ichii M, Brugman MH, Kincade P, Staal FJ. Wnt signaling strength regulates normal hematopoiesis and its deregulation is involved in leukemia development. Leukemia 2012; 26: 414-421.

35. Benz C, Bleul CC. A multipotent precursor in the thymus maps to the branching point of the $T$ versus B lineage decision. J Exp Med 2005; 202: 21-31.

36. Lustig B, Jerchow B, Sachs M, Weiler S, Pietsch T, Karsten U et al. Negative feedback loop of Wnt signaling through upregulation of conductin/axin2 in colorectal and liver tumors. $\mathrm{Mol}$ Cell Biol 2002; 22: 1184-1193.

37. Sugimura R, He XC, Venkatraman A, Arai F, Box A, Semerad C et al. Noncanonical Wnt signaling maintains hematopoietic stem cells in the niche. Cell 2012; 150: 351-365.

38. Baba Y, Garrett KP, Kincade PW. Constitutively active beta-catenin confers multilineage differentiation potential on lymphoid and myeloid progenitors. Immunity 2005; 23 : 599-609.

39. Liang H, Chen Q, Coles AH, Anderson SJ, Pihan G, Bradley A et al. Wnt5a inhibits B cell proliferation and functions as a tumor suppressor in hematopoietic tissue. Cancer Cell 2003; 4: 349-360.

40. Khoo ML, Carlin SM, Lutherborrow MA, Jayaswal V, Ma DD, Moore JJ. Gene profiling reveals association between altered Wnt signaling and loss of T-cell potential with age in human hematopoietic stem cells. Aging Cell 2014; 13: 744-754.

41. Florian MC, Nattamai KJ, Dorr K, Marka G, Uberle B, Vas V et al. A canonical to noncanonical Wnt signalling switch in haematopoietic stem-cell ageing. Nature 2013; 503: 392-396.

42. Balciunaite G, Keller MP, Balciunaite E, Piali L, Zuklys S, Mathieu YD et al. Wnt glycoproteins regulate the expression of FoxN1, the gene defective in nude mice. Nat Immunol 2002; 3: 1102-1108.

43. Tiemessen MM, Staal FJ. Wnt signaling in leukemias and myeloma: T-cell factors are in control. Future Oncol 2013: 9: 1757-1772.

44. Tiemessen MM, Baert MR, Schonewille T, Brugman MH, Famili F, Salvatori DC et al. The nuclear effector of Wnt-signaling, Tcf1, functions as a T-cell-specific tumor suppressor for development of lymphomas. PLOS Biol 2012; 10: e1001430.

45. Martins VC, Busch K, Juraeva D, Blum C, Ludwig C, Rasche V et al. Cell competition is a tumour suppressor mechanism in the thymus. Nature 2014; 509: 465-470.

46. Wilson A, Trumpp A. Bone-marrow haematopoietic-stem-cell niches. Nat Rev Immunol 2006; 6: 93-106.

(c) (i) Cell Death and Disease is an open-access journal cc) published by Nature Publishing Group. This work is licensed under a Creative Commons Attribution 4.0 International License. The images or other third party material in this article are included in the article's Creative Commons license, unless indicated otherwise in the credit line; if the material is not included under the Creative Commons license, users will need to obtain permission from the license holder to reproduce the material. To view a copy of this license, visit http://creativecommons.org/licenses/by/4.0/ 